\title{
BEHAVIOR BASED SAFETY SEKTOR INFORMAL BECAK MOTOR DI YOGYAKARTA
}

\author{
Sri Yuni Tursilowati ${ }^{1)}$, Julaikah ${ }^{2}$ \\ 1,2 STIKES Surya Global Yogyakarta \\ e-mail: julaikah29@gmail.com
}

\begin{abstract}
ABSTRAK
Peningkatan jumlah pengguna becak motor dan peningkatan eksistensi dimata penumpang Yogyakarta tidak lantas menjadikan dinas perhubungan DIY merekomendasikan becak motor sebagai salah satu angkutan yang berkeselamatan, hal ini dikarenakan beberapa kasus kecelakaan yang menimpa becak motor akibat konstruksi angkutan yang kurang baik dan perilaku pengemudi yang dinilai kurang selamat. Pada tahun 2016 sebuah media nasional mengabarkan bahwa selama kurun waktu 2015 di makasar telah terjadi 13 kasus kecelakaan becak motor yang mengakibatkan 3 orang meninggal dunia. Penelitian ini merupakan penelitian kombinasi (mix method) yang menggunakan desain deskriptif. Metode pengumpulan data kuantitatif dalam penelitian ini dilakukan dengan menggunakan kuesioner secara personal. Sedangkan data kualitatif didapatkan dengan wawancara terstruktur kepada reponden dan observasi untuk checklist kegiatan. Populasi dalam penelitian seluruh anggota Paguyuban Becak Motor Yogyakarta (PMBY) dengan sampel 94 orang. Variabel dalam penelitian ini adalah komponen Behavior Based Safety (BBS) dan perilaku keselamatan pengemudi becak motor. Analisa data kuantitatif menggunakan Software smart PLS 3.0. hasil uji kuantitatif menunjukkan variabel yang saling berpengaruh yaitu pengetahuan dengan intensi yang memiliki P-value 0,042. Intensi dengan perilaku P-value 0,016. Persepsi dengan perilaku 0,019. Sedangkan variabel yang tidak saling berpengaruh adalah, persepsi dengan intensi 6,057. Pengetahuan dengan persepsi 1.035 dan pengetahuan dengan perilaku 0,374. Sedangkan data pendukung kualitatif menunjukkan hasil bahwa tidak ada hubungan antara pengetahuan dengan perilaku keselamatan pengendara becak motor serta minimnya perlengkapan keselamatan yang dimiliki oleh pekerja sehingga perilaku selamat belum dapat diwujudkan. Pengendara bentor yang memiliki pengetahuan yang bagus dan niat yang bagus namun tidak didukung dengan sarana prasarana dan kebijakan keselamatan yang memadai maka tidak akan berperilaku keselamatan yang baik dalam berkendara.
\end{abstract}

Kata Kunci: Behavior Based Safety, Safety Driving, Becak Motor.

\begin{abstract}
There is an increasing number of the motorized pedicab and increasing existence among passengers in Yogyakarta do not necessarily make the Yogyakarta Special Territory (DIY) Transportation Agency recommends the motorized pedicab as one of the safe transports. This is the result of several cases of accidents that happen to the motorized pedicab due to the poor construction and the unsafe behavior among motorized pedicab drivers. The national media in 2006 reported that there were 13 motorized pedicab accidents in 2015 that resulted in 3 deaths. This was a mix method research that applied a descriptive design. Quantitative data collection methods were conducted using a personal questionnaire. Meanwhile, qualitative data was obtained by performing structured interviews with respondents and observations for the activity checklist. The population was all members of the Yogyakarta Motorized Pedicab Association (PMBY) with population 270 and the sample 94 people. The variables included the BBS components and the safety behavior of motorized pedicab drivers. Quantitative data
\end{abstract}


analysis used SmartPLS 3.0 Software. Knowledge with perception showed a P value of 1.035 and knowledge with behavior showed a P value of 0.374. Quantitative test results showed interrelated variables, namely knowledge with the intention that had a P-value of 0.042. Intention variable with the behavior showed a P value of 0.016. Perception with behavior showed a $P$ value of 0.019. Meanwhile, uncorrelated variable was perception with the intention of a $P$ value of 6.057. Knowledge with perceptions showed a $P$ value of a 1.035 and knowledge with behavior showed a $P$ value of 0.374. Meanwhile, qualitative supporting data revealed that there was no correlation between knowledge and safety behavior among motorized pedicab drivers as well as the lack of safety equipment workers had so that safety behaviour cannot be practiced yet. Motorized pedicab drivers with good knowledge and good intentions but are not supported with adequate infrastructure and facilities as well as safety policies will not practice safe driving.

Keywords: Behavior Based Safety, Safety Driving, Motorized Pedicab

\section{PENDAhULUAN}

Becak motor telah ada di Yogyakarta sejak tahun 2008 dan bernaung di bawah Paguyuban Becak Motor Yogyakarta (PBMY) sejak tahun 2009 walaupun belum mendapatkan ijin secara legal namun jumlahnya semakin meningkat dan menjadi pilihan bagi penumpang (Radar Jogja, 2017). Peningkatan jumlah pengguna dan peningkatan eksistensi dimata penumpang tidak lantas menjadikan dinas perhubungan Yogyakarta merekomendasikan becak motor sebagai salah satu angkutan yang berkeselamatan, hal ini dikarenakan beberapa kasus kecelakaan yang menimpa becak motor akibat konstruksi angkutan yang kurang baik dan perilaku pengemudi yang dinilai kurang selamat (ANTARA News, 2018). ILO yang merupakan organisasi buruh sedunia merilis data rata-rata kecelakaan kerja di Indonesia per tahun yang mencapai angka 99.000 dengan 20 kasus fatal yang menyebabkan pekerja meninggal dunia.

Keselamatan pekerja dalam berbagai sector kerja tentunya penting untuk diperhatikan baik yang berasal dari sector formal maupun informal. Becak motor yang berasal dari sektor informal juga tidak bisa kita lepaskan dari perhatian. Pada tahun 2016 sebuah media nasional mengabarkan bahwa selama kurun waktu 2015 di makasar telah terjadi 13 kasus kecelakaan becak motor yang mengakiatkan 3 orang meninggal dunia (Tribun Timur, 2016). Kecelakaan kerja $88 \%$ terjadi dikarenakan perilaku manusia yang tidak aman atau unsafe act sedangkan $10 \%$ oleh lingkungan kerja yang tidak aman atau unsafe condition dan $2 \%$ karena faktor lainnya (Chen \& Tian, 2012). Hasil penelitian tersebut menyatakan bahwa 98\% indikator kecelakaan dapat dicegah dengan mengontrol kebiasaan manusia. Pernyataan ini diperkuat oleh Dominic Cooper (2009) yang berpendapat walaupun sulit untuk di kontrol secara tepat, 80-95 persen dari seluruh kecelakaan kerja yang terjadi disebabkan oleh unsafe behavior (Cooper, 2001).

Berdasarkan data dan permasalahan diatas peneliti tertarik untuk melakukan penelitian tentang budaya keselamatan/Behavior Based Safety (BBS) pengguna becak motor di kawasan kota Yogyakarta dengan harapan akan didapatkannya hasil yang mampu memberikan informasi dan gambaran keadaan lapangan sehingga dapat dibuat kebijakan yang relevan dengan kebutuhan 
keselamatan pengguna becak motor di Yogyakarta.

Keselamatan kerja merupakan upaya manusia agar pemanfaatan teknologi yang ditemukan manusia untuk menghasilkan produk dan jasa pada kegiatan operasi dapat dikendalikan risikonya dengan berlandaskan ilmu dan teknologi sehingga insiden yang mengakibatkan kerugian pada manusia dapat dicegah. Sebagai upaya pencegahan terjadinya kecelakaan kerja maka diperlukan adanya program keselamatan yang mana program tersebut dikembangkan dari berbagai pendekatan seperti pendekatan rekayasa dan pendekatan perilaku, yang pada masa sekarang mulai di kembangkan lagi menjadi pendekatan perilaku dan pendekatan budaya. Budaya keselamatan berfungsi untuk meminimalkan kemungkinan kecelakaan akibat kesalahan yang dilakukan individu. Meningkatkan kesadaran akan bahaya jika melakukan kesalahan dalam bertindak dan berperilaku. Mendorong pekerja untuk menjalani setiap prosedur dalam semua tahap pekerjaan. Mendorong pekerja untuk melaporkan kesalahan/kekurangan sekecil apapun yang terjadi untuk menghindari terjadinya insiden dan kecelakaan (Waluyo, 2015).

BBS merupakan sebuah desain pendekatan yang digunakan untuk mengembangkan keselamatan di tempat kerja yang berfokus pada perilaku selamat (Agraz-boeneker, Groves, \& Haight, 2007). Selain itu juga BBS merupakan metode yang paling tepat digunakan untuk merubah perilaku tidak aman pada manusia karena, BBS adalah salah satu metode yang efektif untuk mencegah kecelakaan yang terjadi di negaranegara amerika dan eropa sejak tahun 1980, selain itu juga beberapa penelitian menunjukkan bahwa hal ini juga berlaku di china. Hal ini dapat dibuktikan melalui indeks performa kecelakaan, seperti rata-rata jumlah kecelakaan yang berubah (Chen \& Tian, 2012). BBS di dasarkan pada empat komponen utama yaitu: kesadaran situasional dan observasi, proses umpan balik informal, menentukan tujuan perbaikan, tindak lanjut atas pencapaian tujuan (Rinawati, 2018).

Perilaku Activator-BehaviorConsequence (ABC) merupakan model perilaku yang biasanya digunakan dalam penerapan Risk Behavior Based Safety. Model perilaku $A B C$ merupakan model analisis terapan yang dikemukakan oleh Skinner B.P tahun 1980 dan dipopulerkan oleh Thomas $\mathrm{R}$ Krause guna untuk melakukakan perbaikan kinerja keselamatan yang berkelanjutan. Model perilaku ABC menjelaskan mengapa sebagai penggerak kita melakukan APA yang kita lakukan serta persepsi akan dampak atau akibat dari perilaku. Model perilaku ABC ialah suatu model perubahan perilaku yang terdiri dari $\mathrm{ABC}$ yang cocok digunakan untuk mempromosikan perilaku Keselamatan dan Kesehatan Kerja (Waluyo, 2015). Model perilaku ABC digunakan untuk memahami mengapa perilaku bisa terjadi serta merupakan cara yang efektif untuk meningkatkan perilaku yang diharapkan karena dalam model perilaku $\mathrm{ABC}$ terdapat konsekuensi yang dapat digunakan untuk memotivasi agar frekuensi perilaku yang diharapkan dapat meningkat. Selain itu, model perilaku ABC berguna untuk mendesain intervensi yang dapat meningkatkan perilaku individu, kelompok, dan organisasi. Perilaku yang diharapkan untuk meningkat dalam hal ini adalah perilaku aman atau perilaku selamat (Julaikah, 2017). Paradigma perilaku keselamatan dengan memanfaatkan 
elemen ABC dijelaskan oleh Geller sebagai berikut:

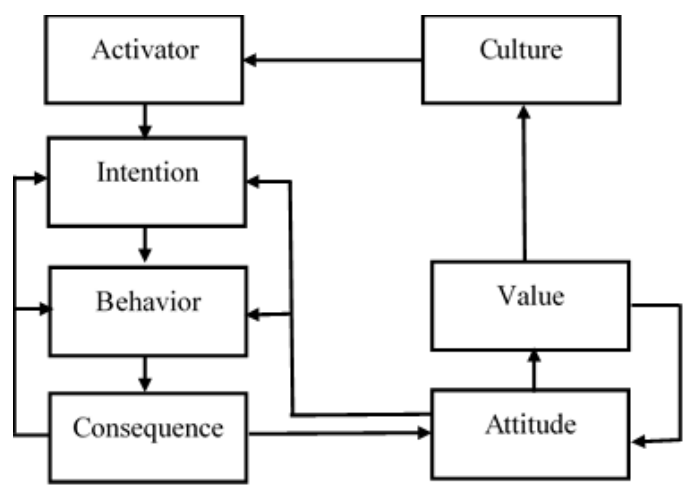

Gambar 1. Paradigm shift for total safety (Geller, 2001)

Activator merupakan penggerak perilaku yang menghasilkan intensi berperilaku serta pemahaman terhadap dampak sebuah perilaku. Proses pemahaman terhadap dampak akan menghasilkan sikap dan value seseorang terhadap sebuah keadaan, namun demikian sikap juga mempengaruhi perilaku dan niat sekaligus secara langsung. Keberlangsungan dari semua proses akan menghasilkan budaya, yaitu sebuah perilaku yang didasari oleh nilai dan berbagai kepahaman yang lainnya.

\section{METODE PENELITIAN}

Penelitian ini merupakan penelitian kombinasi (mix method) yang menggunakan desain deskriptif dan dilaksanakan pada Juli-Agustus 2019 di Yogyakarta menggunakan pendekatan cross sectional. Populasi dalam penelitian ini adalah pengemudi becak motor yang terdaftar dalam Paguyuban Becak Motor Kota Yogyakarta dengan jumlah 270 anggota. Teknik penghitungan sampel yang digunakan adalah rumus SLOVIN dengan tingkat alfa $10 \%$ sebanyak 72.9 sampel yang kemudian dibulatkan menjadi 94 sampel. Teknik pengambilan sampel menggunakan metode purposive sampling sedangkan instrumen yang digunakan dalam penelitian ini adalah kuesioner terstruktur dan pedoman wawancara serta lembar observasi.

Metode pengumpulan data kuantitatif dalam penelitian ini dilakukan dengan menggunakan kuesioner secara personal. Prosedur pengumpulan data dilakukan dengan memberikan kuesioner kepada responden sekaligus peneliti melakukan wawancara terhadap responden secara personal dengan menanyakan pertanyaan sesuai kuesioner. Sedangkan data kualitatif didapatkan dengan wawancara terstruktur kepada reponden dan observasi untuk checklist kegiatan.

Teknik analisis data kuantitatif yang digunakan untuk menjawab rumusan masalah atau menguji hipotesis yang telah dirumuskan. Pengelolaan data pada penelitian ini akan menggunakan Software smartPLS 3.0. Dalam metode PLS (Partial Least Square) teknik analisa yang dilakukan adalah sebagai berikut:

a. Analisa outer model dilakukan untuk memastikan bahwa measurement yang digunakan layak untuk dijadikan pengukuran (valid dan reliabel) yakni Convergent Validity, Discriminant Validity, Composite reliability dan Cronbach's Alpha

b. Analisa Inner model biasanya juga disebut dengan (inner relation, structural model dan substantive theory) yang mana menggambarkan hubungan antara variabel laten berdasarkan pada substantive theory. Dalam pengevaluasian inner model dengan PLS (Partial Least Square) dimulai dengan cara melihat $R$-square untuk setiap variabel laten dependen. Kemudian dalam penginterpretasiannya sama dengan interpretasi pada regresi. 
c. Pengujian hipotesa dapat dilihat dari nilai t-statistik dan nilai probabilitas. Untuk pengujian hipotesis yaitu dengan menggunakan nilai statistik maka untuk alpha 5\% nilai t-statistik yang digunakan adalah 1,96. Sehingga kriteria penerimaan/penolakan hipotesa adalah Ha diterima dan $\mathrm{H} 0$ di tolak ketika t-statistik > 1,96. Untuk menolak/menerima hipotesis menggunakan probabilitas maka Ha di terima jika nilai $\mathrm{p}<0,05$.

\section{HASIL DAN PEMBAHASAN}

Responden pada penelitian ini adalah Paguyuban Becak Motor Kota Yogyakarta. Karakteristik ini meliputi usia dan masa kerja sebagai pengemudi becak motor. Berikut adalah data dari kedua karakteristik tersebut:

Tabel 1. Jumlah responden menurut jenis kelamin (n: 94)

\begin{tabular}{lcc}
\hline $\begin{array}{l}\text { Jenis } \\
\text { Kelamin }\end{array}$ & Jumlah & $\begin{array}{c}\text { Prosentase } \\
(\%)\end{array}$ \\
\hline Laki - laki & 94 & $100 \%$ \\
\hline
\end{tabular}

Sumber: Data Primer Diolah, 2019

Berdasarkan pada tabel diatas diketahui bahwa $100 \%$ responden dalam penelitian ini adalah laki-laki. Selain jenis kelamin, responden juga dibedakan berdasarkan usia, berikut adalah tabel usia responden:

Tabel 2. Jumlah responden menurut usia (n:94)

\begin{tabular}{ccc}
\hline Usia & Jumlah & $\begin{array}{c}\text { Prosentase } \\
(\boldsymbol{\%})\end{array}$ \\
\hline$\leq 25$ & 0 & 0 \\
$\geq 26-\leq 45$ & 89 & 94,7 \\
$\geq 46-\leq 55$ & 5 & 5,3 \\
\hline Total & 94 & $100 \%$ \\
\hline
\end{tabular}

Sumber: Data Primer Diolah, 2019
Berdasarkan data distribusi frekuensi diatas dapat kita ketahui bahwa rentang persebaran usia responden $94.7 \%$ berada pada rentang usia $\geq 26$ - $\leq 45$ yang dengan kata lain 89 responden berada pada fase usia produktif. Sisanya, $5.3 \%$ responden masuk dalam rentang usia $\geq 46-\leq 55$ atau bukan usia produktif.

Tabel 3. Jumlah responden menurut masa kerja sebagai Pengemudi Becak Motor

\begin{tabular}{lcc}
\hline Masa Kerja & Jumlah & $\begin{array}{c}\text { Persentase } \\
(\boldsymbol{\%})\end{array}$ \\
\hline 1-5 tahun & 57 & 60,6 \\
6-10 tahun & 22 & 23,4 \\
11-15 tahun & 9 & 9,6 \\
16-20 tahun & 4 & 4,3 \\
>20 tahun & 2 & 2,1 \\
\hline \multicolumn{1}{c}{ Total } & 94 & 100 \\
\hline
\end{tabular}

Sumber: Data Primer Diolah, 2019

Masa kerja yang dimaksud dalam penelitian ini adalah masa kerja pengemudi becak motor dalam mengemudikan becak motornya. Masa kerja tidak dihirung dengan mempertimbangkan masa kerja sebelumnya sebagai pengemudi becak kayuh. Sehingga penghitungan masa kerja dimulai sejak pertama kali responden mengemudikan becak motor. Dari Tabel 3 dapat diketahui bahwa karakteristik responden berdasarkan lama menjadi pengemudi becak motor pada 1-5 tahun hasilnya adalah 57 orang atau $60,6 \%$, lama menjadi pengemudi becak motor pada 6-10 tahun hasilnya adalah 22 orang atau $23,4 \%$, lama menjadi pegnemudi becak motor pada 16-20 tahun hasilnya adalah 4 orang atau $4,3 \%$, lama menjadi pengemudi becak morot pada $>20$ tahun hasilnya adalah 2 orang atau $2,1 \%$. 
Tabel 4. Jumlah responden berdasarkan kepemilikan SIM (n: 94)

\begin{tabular}{ccc}
\hline $\begin{array}{c}\text { Kepemilikan } \\
\text { SIM }\end{array}$ & Jumlah & $\begin{array}{c}\text { Prosentase } \\
(\boldsymbol{\%})\end{array}$ \\
\hline Tidak punya & 20 & 21,3 \\
Punya & 74 & 78,7 \\
\hline Total & 94 & 100,0 \\
\hline
\end{tabular}

Sumber: Data Primer Diolah, 2019

Berdasarkan Tabel 4 diatas kita dapat melihat data responden yang memiliki SIM C adalah 78,7 \% sedangkan sisanya $21,3 \%$ tidak memiliki SIM.

Tabel 5. Jumlah responden berdasarkan pengalaman kecelakaan (n: 94)

\begin{tabular}{ccc}
\hline $\begin{array}{c}\text { Pengalaman } \\
\text { Kecelakaan }\end{array}$ & Jumlah & $\begin{array}{c}\text { Prosentase } \\
\mathbf{( \% )}\end{array}$ \\
\hline $\begin{array}{c}\text { Pernah kecelakaan } \\
\text { Tidak pernah } \\
\text { kecelakaan }\end{array}$ & 11 & 11,7 \\
\hline Total & 83 & 88,3 \\
\hline
\end{tabular}

Sumber: Data Primer Diolah, 2019
Berdasarkan Tabel 5 tersebut dapat kita ketahui bahwa pengemudi becak motor yang pernah mengalami kecelakaan adalah $11,7 \%$ dan $88,3 \%$ lainnya tidak pernah mengalami kecelakaan. Kecelakaan yang dimaksud disini adalah kecelakaan yang terjadi selama bekerja atau melakukan pekerjaan sebagai pengemudi becak motor.

Uji hipotesis pada penelitian ini dilakukan dengan melihat nilai $\mathrm{T}$ Statistics dan nilai p-values. Hipotesis penelitian dapat dinyatakan diterima apabila nilai $p$-values $<0,05$. Berikut ini adalah hasil uji hipotesis yang diperoleh dalam penelitian ini.

Tabel 6. Hasil uji statistik hipotesa penelitian

\begin{tabular}{ccccc}
\hline Variabel & $\begin{array}{c}\text { Original } \\
\text { sample } \\
\text { estimate }\end{array}$ & $\begin{array}{c}\text { Mean of } \\
\text { subsamples }\end{array}$ & $\begin{array}{c}\text { Standard } \\
\text { deviation }\end{array}$ & T-Statistic \\
\hline $\begin{array}{c}\text { Pengetahuan -> } \\
\text { intensi }\end{array}$ & -0.007 & 0.103 & 0.168 & 0.042 \\
$\begin{array}{c}\text { Persepsi -> } \\
\text { intensi }\end{array}$ & 0.732 & 0.750 & 0.121 & 6.057 \\
$\begin{array}{c}\text { Pengetahuan -> } \\
\text { persepsi }\end{array}$ & -0.361 & -0.168 & 0.348 & 1.035 \\
$\begin{array}{c}\text { Pengetahuan -> } \\
\text { perilaku } \\
\text { Intensi -> } \\
\text { perilaku }\end{array}$ & 0.117 & 0.161 & 0.312 & 0.374 \\
$\begin{array}{c}\text { Persepsi -> } \\
\text { perilaku }\end{array}$ & -0.005 & 0.021 & 0.311 & 0.016 \\
\hline Sur & -0.007 & 0.018 & 0.339 & 0.019 \\
\hline
\end{tabular}

Sumber: Data Primer Diolah, 2019

Berdasarkan sajian data pada Tabel 6, dapat diketahui ada 6 hipotesis yang diujikan dalam penelitian ini dengan hasil masing-masing variabel yang saling berpengaruh yaitu pengetahuan dengan intensi yang memiliki p-value 0,042 . Intensi dengan perilaku $\mathrm{p}$-value 0,016 . Persepsi dengan perilaku 0,019 . Sedangkan variabel yang tidak saling berpengaruh adalah, persepsi dengan 
intensi 6,057. Pengetahuan dengan persepsi 1.035 dan pengetahuan dengan perilaku 0,374 .

Data kuantitatif yang diperoleh juga didukung dengan data kualitatif yang dikumpulkan peneliti dari kegiatan wawancara dan observasi. Wawancara dalam penelitian ini dilakukan kepada pengambil kebijakan dan pengguna yaitu penumpang dengan pertimbangan bahwa yang bersangkutan merupakan orang yang mengetahui tentang performa perilaku keselamatan pengemudi becak motor dan mampu memberikan tanggapan tentang perilaku keselamatan yang dilakukan. Pemangku kebijakan lebih banyak memberikan tanggapan terkait perilaku dan alasan tidak adanya legalitas operasi yang diberikan oleh pemerintah daerah.

Informasi pendukung yang disampaikan dalam wawancara diantaranya meliputi:

\section{a. Activator}

Ada perbedaan cara pandang terhadap risiko keselamatan yang disampaikan oleh responden. Perwakilan pemerintah daerah menyampaikan bahwa risiko kecelakaan untuk pengemudi becak motor tinggi terlebih dikarenakan desain becak motor belum memiliki standar desain yang memenuhi aspek keselamatan pengemudi dan penumpang, sedangkan, pihak paguyuban menyampaikan bahwa pengemudi merupakan individu yang berpengalaman dan telah memiliki pengetahuan terkait dengan rsisiko keselamatan selama berkendara, baik untuk keselamatan pengemudi maupun keselamatan penumpang. Selain pengetahuan tentang keselamatan fasilitas keselamatan di jalan raya dan juga fasilitas keselamatan yang dimiliki individu dalam hal ini adalah APD juga berperan dalam menentukan perilaku keselamatan pengemudi becak motor.

b. Behavior

Behavior atau perilaku pengendara becak motor yang disampaikan oleh responden dalam wawancara menggambarkan bahwa pengendara becak motor yogyakarta masih belum mampu menerapkan perilaku keselamatan secara menyeluruh. Misalnya, salah satu responden menyampaikan bahwa pernah melihat sendiri terjadinya kecelakaan becak motor dalam situasi becak motor mengantar penumpang sehingga penumpang jatuh dan harus segera diberikan pertolongan.

"Tapi, kami liat beberapa bentor yang ada di kota Yogyakarta khususnya jalan malioboro ini banyak yang ugal-ugalan. Intinya, mereka menjalankan becak motor itu terlalu kencang menurut saya." (RI)

Pernyataan berbeda disampaikan oleh responden lain (R2) yang menyatakan bahwa dalam berkendara keselamatan penumpang adalah prioritas sehingga dalam perjalanan pengemudi selalu menjaga kecepatan dan tidak ugalugalan. Sedangkan responden dari pihak penumpang (R3) menyampaikan bahwa salah satu alasan tetap memilih becak motor sebagai transportasi andalan ketika berkunjung ke Malioboro adalah karena becak motor dapat mengantar ke lokasi tujuan dengan cepat dan praktis, meskipun responden pernah mendapatkan pengalaman mendapatkan pengemudi yang mengendarai kendaraan dengan cepat dan hampir jatuh. 


\section{c. Consequences}

Berdasarkan hasil wawancara dengan responden diperoleh informasi bahwa belum ada upaya peningkatan pengetahuan keselamatan pengemudi becak motor dari pemerintah daerah melalui dinas / institusi terkait yang dilakukan secara periodik ataupun kontinyu dikarenakan becak motor merupakan moda transportasi ilegal di lingkungan DI Yogyakarta. Namun demikian keberadaan moda transportasi ini juga tidak mendapatkan tindakan punishment secara tegas. Pelarangan hanya berlaku jika ada razia atau operasi pamong praja, apabila kegiatan operasi itu sedang tidak berlangsung, ketrangan ini disampaikan oleh responden (R1 \& R2). Sejalan dengan tidak adanya punishment maka pelaksanaan reward dari pemerintah daerah juga tidak berlaku. Pelaksanaan reward dan punishment

Observasi merupakan metode pengumpulan lainnya yang berfungsi sebagai triangulasi data kualitatif dan data kuantitaif. Berikut adalah hasil dari observasi:

1) Elemen keselamatan kendaraan

Perlengkapan keselamatan kendaraan merupakan elemen yang penunjang dalam perilaku keselamatan pengendara becak motor.

Gambar 2. Grafik kelengkapan elemen keselamatan kendaraan becak motor

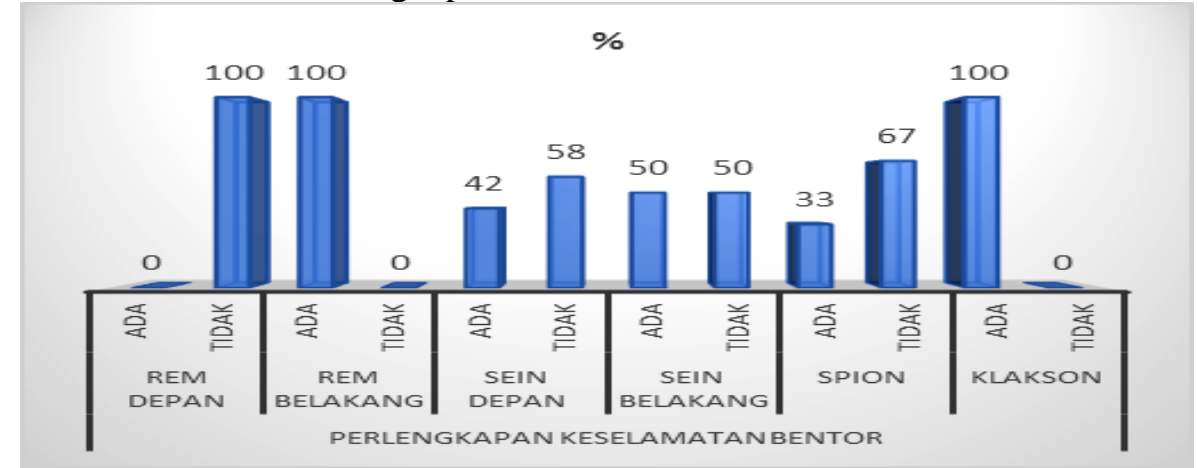

Sumber: Data Primer Diolah, 2019

Pada grafik diatas kita dapat melihat bahwa perlengkapan keselamatan kendaraan pada sampel memiliki fluktuasi yang berbeda seperti misalnya rem depan $0 \%$, rem belakang $100 \%$, sein depan $42 \%$ tersedia, sein belakang $50 \%$, spion 33\%, dan klakson $100 \%$. Sedangkan berdasarkan perhitungan ratarata ketersediaan perlengkapan keselamatan bentor dari total responden yang ada adalah $28,57 \%$ dari total kebutuhan perlengkapan yang harus dimiliki oleh bentor.

2) Elemen alat pelindung diri pengendara

Perlengkapan pelindung diri berfungsi untuk melindungi keselamatan pengendara bentor dari dampak terjadinya kecelakaan. Komponen alat pelindung diri yang diukur dalam penelitian ini adalah 
helm, masker, pelindung mata, sarung tangan, jaket/rompi pelindung,

pelindung kaki (tertutup), celana dan baju panjang.

Gambar 3. Grafik kelengkapan alat pelindung diri pengemudi becak motor

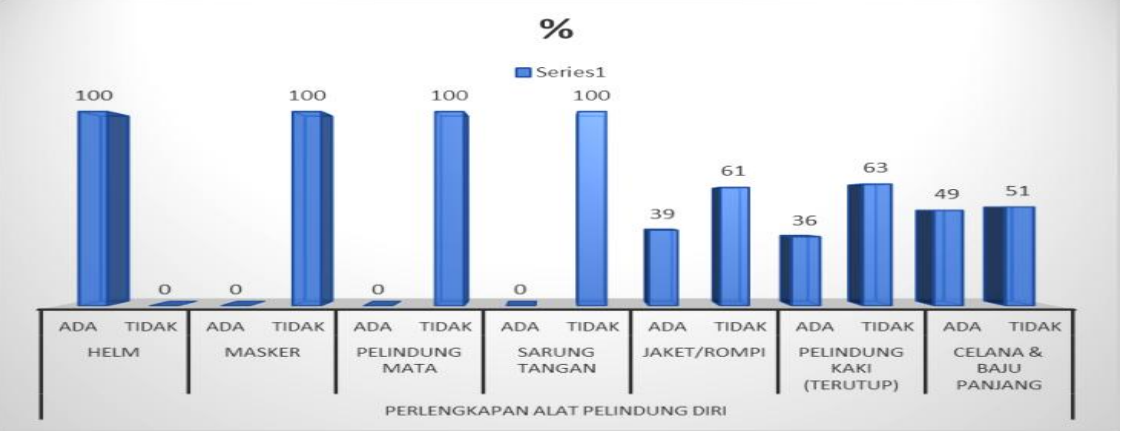

Sumber: Data Primer Diolah, 2019

Dari hasil pengukuran yang dilakukan diperoleh hasil yang bervariasi dari masing-masing alat pelindung diri yaitu : helm sesuai SNI $100 \%$, masker $0 \%$, pelindung mata $100 \%$, sarung tangan $0 \%$, jaket/rompi $39 \%$, pelindung kaki tertutup $36 \%$, celana \& baju panjang $49 \%$. Sedangkan berdasarkan perhitungan rata-rata dari total responden kelengkapan alat pelindung diri yang bisa dipenuhi adalah 37,9\% .

Budaya keselamatan merupakan interelasi dari tiga elemen, yaitu organisasi, pekerja, dan pekerjaan. Hal ini menunjukkan bahwa budaya keselamatan harus dilaksanakan oleh seluruh sumber daya yang ada, pada seluruh tingkatan dan tidak hanya berlaku untuk pekerja saja (Suyono \& Nawawinetu, 2013) dalam konteks sektor informal becak motor tentu saja hal ini menjadi berbeda karena sektor informal tidak diatur oleh sebuah manajemen perusahaan namun teori ini juga masih relevan untuk digunakan dengan mengganti konteks organisasi dengan pembuat kebijakan yang dalam hal ini adalah Pemerintah Daerah Kota Yogyakarta.

Penelitian ini berfokus pada varibel pembentuk BBS atau perilaku berbasis keselamatan. Variabel pembentuk perilaku keselamatan diantaranya adalah Tiga variabel dalam penelitian ini tidak saling memiliki hubungan persepsi dengan intensi 6,057. Pengetahuan dengan persepsi 1.035 dan pengetahuan dengan perilaku 0,374 hal ini didukung dengan data checklist observasi yang menunjukkan bahwa perlengkapan alat pelindung diri pengemudi becak motor yang lengkap $100 \%$ dimiliki hanya helm, sisanya sisanya seperti baju panjang, celana panjang dan rompi berada dibawah 50\% sedangkan masker, pelindung mata dan sarung tangan adalah $0 \%$. Selain data diatas, perilaku keselamatan pengendara yang tidak berhubungan dengan pengetahuan yang dimiliki juga dibenarkan oleh pemangu kebijakan yang menyatakan.

"Tapi, kami liat beberapa bentor yang ada di kota Yogyakarta khususnya Jalan Malioboro ini banyak yang ugal-ugalan. Intinya, mereka menjalankan becak motor itu terlalu kencang menurut saya." (RI)

Hasil ini sesuai dengan penelitian yang dilakukan pada siswa SMK PGRI 4 Surabaya yang mana dalam penelitian tersebut didapatkan hasil $\mathrm{P}$ Value 1,921 dari uji chi square variabel pengetahuan dengan perilaku yang bermakna tidak ada hubungan yang signifikan (Muryatma, 2018). Begitu juga hasil penelitian yang disampaikan oleh rinawati, dkk bahwa 
seseorang yang memiliki pendidkan formal tinggi tidak lantas menjamin yang bersangkutan berperilaku aman (Rinawati, Widowati, \& Rosanti, 2016).

Variabel yang memiliki hubungan antara satu dengan yang lainnya diantaranya adalah pengetahuan dengan intensi yang memiliki P-value 0,042 . Pengetahuan merupakan hal yang penting dan pertama kali diperlukan seseorang untuk mengadopsi suatu perilaku baru (Notoadmodjo, 2002). Pengetahuan ini meliputi tata cara berkendara dan penggunaan alat pelindung diri dalam berkendara, perawatan kendaraan, pengenalan kapasistas muatan dan kecepatan laju kendaraan sesuai dengan ketentuan. Pengetahuan memang tidak memiliki hubungan yang signifikan dengan perilaku namun signifikan dengan persepsi perilaku selamat dan berdasarkan hasil uji statistic ini juga didapatkan nilai yang signifikan antara persepsi dengan perilaku selamat pekerja. Dalam hasil wawancara responden (R2) menyatakan bahwa dalam berkendara keselamatan penumpang adalah prioritas sehingga dalam perjalanan pengemudi selalu menjaga kecepatan dan tidak ugal-ugalan.

Berdasarkan hasil penelitian diketahui bahwa terdapat pengaruh signifikan antara persepsi terhadap bahaya dan risiko kecelakaan terhadap safe behavior tenaga kerja. Hal ini dapat terjadi karena tenaga kerja memiliki persepsi yang tepat terhadap bahaya dan risiko kecelakaan di lingkungan kerja mereka sehingga tenaga kerja berperilaku aman untuk menghindari bahaya dan risiko kecelakaan kerja sebagaimana yang mereka persepsikan. Sebaliknya apabila tenaga kerja memiliki persepsi yang tidak tepat, tenaga kerja hanya akan memikirkan pekerjaan mereka dapat terselesaikan dengan cepat tanpa memikirkan risiko dan bahaya kecelakaan, sehingga hal tersebut dapat berdampak pada terciptanya perilaku tidak aman (Retnani \& Ardyanto, 2013).

Persepsi pekerja yang berkorelasi positif dengan peningkatan perilaku aman merupakan sebuah sinyal positif yang bisa mengarahkan pekerja untuk meningkatkan perilaku amannnya. Selain itu, adanya pemahaman tentang pentingya penggunaan alat pelindung diri juga diperlukan mengingat masih rendahnya kesadaran pengemudi becak motor terhadap penggunaan APD selama bekerja dan perlunya perhatian terhadap perlengkapan peralatan keselamatan kendaraan terutama sein dan lampu sepion sebab keselamatan berkendara tidak dapat berdiri sendiri tanpa melibatkan pengendara yang lain.

\section{KESIMPULAN}

Behavior based safety pengendara becak motor Kota Yogyakarta dipengaruhi oleh berbagai macam faktor diantanya adalah pengetahuan dengan intensi yang memiliki P-value 0,042 . Intensi dengan perilaku $\mathrm{P}$-value 0,016 . Persepsi dengan perilaku 0,019 . Sedangkan variabel yang tidak saling berpengaruh adalah, persepsi dengan intensi 6,057. Pengetahuan dengan persepsi 1.035 dan pengetahuan dengan perilaku 0,374. Pengendara bentor yang memiliki pengetahuan yang bagus dan niat yang bagus namun tidak didukung dengan sarana prasarana dan kebijakan keselamatan yang memadai maka tidak akan berperilaku keselamatan yang baik dalam berkendara.

\section{SARAN}

Kebijakan keselamatan berkendara
bagi pengemudi becak motor
diperlukan, mengingat becak motor
merupakan alternatif pilihan
transportasi bagi masyarakat dan


wisatawan yang berkunjung ke Yogyakata. Selain itu juga penting untuk dipertimbangkan adanya pelatihan dan sosialisasi keselamatan secara kontinyu agar perpsepsi keselamatan pengendara meningkat sehingga akan berdampak pada peningkatan perilaku keselamatan pekerja (pengemudi becak motor) sesuai dengan hasil uji statistik yang telah dilakukan.

\section{TERIMA KASIH}

Terimakasih kepada Kementrian Riset dan Pendidikan Tinggi sebagai penyandang dana penelitian ini melalui Program Penelitian Dosen Pemula Tahun Anggaran 2018.

\section{REFERENSI}

Agraz-boeneker, B. R., Groves, W. A., \& Haight, J. M. 2007. An Examination of Observations and Incidence Rates for a Behavior Based Safety Program. The Journal of $S H \& E$ Research, 4(3), 1-22.

ANTARA News. 2018. Yogyakarta tidak rekomendasikan becak motor sebagai angkutan. Retrived from https://jogja.antaranews.com/

Chen, D., \& Tian, H. 2012. Behavior based safety for accidents prevention and positive study in China construction project. Procedia Engineering, 43, 528-534. https://doi.org/10.1016/j.proeng.201 2.08 .092

Cooper, D. 2001. Improving Safety Culture: A Practical Guide. https://doi.org/10.1017/CBO978110 7415324.004

Geller, E. S. 2001. The Psychology of Safety Hanbook -2nd Edition (2 nd). Retrieved from http://www.ghbook.ir/

Julaikah. 2017. Peran Consequences (C) dalam Penggunaan Alat Pelindung Diri pada Pekerja UPT Balai Yasa Yogyakarta. Medika Respati, 13suplem(13), 10-17. Retrieved from http://medika.respati.ac.id/index.php /Medika/article/view/136

Muryatma, N. M. 2018. Hubungan Antara Faktor Keselamatan Berkendara Dengan Perilaku Keselamatan Berkendara. Jurnal PROMKES, 5(2), 155. https://doi.org/10.20473/jpk.v5.i2.20 17.155-166

Notoadmodjo, S. 2002. Pendidikan dan perilaku kesehatan. Rineka Cipta.

Radar Jogja. 2017. Becak Motor Belum Miliki Aturan, Dinilai Ilegal. Retrieved from https://radarjogja.co/

Retnani, N. D., \& Ardyanto, D. 2013. ANALISIS PENGARUH

ACTIVATOR DAN CONSEQUENCE TERHADAP SAFE BEHAVIOR PADA TENAGA KERJA DI PT . PUPUK KALIMANTAN TIMUR TAHUN 2013. The Indonesian Journal of Occupational Safety and Health, vol 2: 2, 119-129.

Rinawati, S. 2018. LEVEL OF SAFE BEHAVIOR WITH THE IMPLEMENTATION OF HOT WORK PERMIT APPROACH IN PT BBB EAST JAVA. Journal of Vocational Health Studies, 01, 8996. https://doi.org/10.20473/jvhs.

Rinawati, S., Widowati, N. N., \& Rosanti, E. 2016. Pengaruh Tingkat Pengetahuan Terhadap Pelaksanaan Pemakaian Alat Pelindung Diri Sebagai Upaya Pencapaian Zero Accident Di Pt. X. Journal of Industrial Hygiene and Occupational Health, 1(1), 53. https://doi.org/10.21111/jihoh.v1i1. 606

Suyono, K. Z., \& Nawawinetu, E. D. 2013. Keselamatan Kerja Dengan Safety Behavior Di Pt Dok Dan Perkapalan Surabaya Unit Hull Construction. The Indonesian Journal of Occupational Safety and Health, 2, 67-74. 
Tribun Timur. 2016. Kecelakaan Bentor Banyak Disebabkan Pengemudi Ugal-ugalan - Tribunnews. Retrieved from https://www.tribunnews.com/region al/sulawesi
Waluyo, F. A. G. 2015. Risk Based Behavioral Safety "Membangun Kebersamaan Untuk Mewujudkan Keunggulan Operasi”. Jakarta: Kompas Gramedia. 